\title{
POROUS MEDIA MATRIC POTENTIAL AND WATER CONTENT MEASUREMENTS DURING PARABOLIC FLIGHT
}

\author{
Joey H. Norikane, ${ }^{*}$ Scott B. Jones, $\uparrow$ Susan L. Steinberg, $\ddagger$ Howard G. Levine, $\S$ and Dani Or $\llbracket$ \\ * Biosystems and Agricultural Engineering Department, \\ University of Kentucky, Lexington, KY 40546-0276 \\ $\dagger$ Department of Plants, Soils and Biometeorology, Utah State University, Logan, UT 84322-4820 \\ ¥Universities Space Research Association, Johnson Space Center/NASA, Houston, TX 77058 \\ §NASA Biological Sciences Office, Kennedy Space Center, FL 32899 \\ TICivil and Environmental Engineering Department, \\ University of Connecticut, Storrs, CT 06269-2037
}

\begin{abstract}
Control of water and air in the root zone of plants remains a challenge in the microgravity environment of space. Due to limited flight opportunities, research aimed at resolving microgravity porous media fluid dynamics must often be conducted on Earth. The NASA KC-135 reduced gravity flight program offers an opportunity for Earth-based researchers to study physical processes in a variable gravity environment. The objectives of this study were to obtain measurements of water content and matric potential during the parabolic profile flown by the KC-135 aircraft. The flight profile provided 20-25 s of microgravity at the top of the parabola, while pulling $1.8 \mathrm{~g}$ at the bottom. The soil moisture sensors (Temperature and Moisture Acquisition System: Orbital Technologies, Madison, WI) used a heat-pulse method to indirectly estimate water content from heat dissipation. Tensiometers were constructed using a stainless steel porous cup with a pressure transducer and were used to measure the matric potential of the medium. The two types of sensors were placed at different depths in a substrate compartment filled with 1-2 mm Turface (calcined clay). The ability of the heat-pulse sensors to monitor overall changes in water content in the substrate compartment decreased with water content. Differences in measured water content data recorded at 0,1 , and $1.8 \mathrm{~g}$ were not significant. Tensiometer readings tracked pressure differences due to the hydrostatic force changes with variable gravity. The readings may have been affected by changes in cabin air pressure that occurred during each parabola. Tensiometer porous membrane conductivity (function of pore size) and fluid volume both influence response time. Porous media sample height and water content influence time-to-equilibrium, where shorter samples and higher water content achieve faster equilibrium. Further testing is needed to develop these sensors for space flight applications.
\end{abstract}

Key words: Heat-pulse soil moisture sensors; KC-135; Microgravity; Tensiometers; Turface

\section{INTRODUCTION}

The key to successful plant research or crop production in space is to understand the effect of microgravity on plant physiological functions. Problems controlling the plant environment have made it impossible to isolate microgravity as a variable of study (6). In particu- lar, control of water and air in the root zone of plants has been one of the most complex issues to address (8). Difficulty controlling water and air in the root zone have been inferred from soil and plant measurements $(2,3,16,17)$. This is also a topic under investigation in the Water Offset Nutrient Delivery Experiment (WONDER) spaceflight experiment $(5,9,10)$. 
Despite nearly 20 years of plant research in microgravity, little attention has been paid to gaining a fundamental understanding of the flow and distribution of water and air in porous media in microgravity (22). The work by Podolsky and Mashinsky (15) and Jones and Or (8) represents the first attempts to put transporting air and water on a sound theoretical basis. However, the current understanding of the nature of water and air transport in microgravity is still not sufficiently developed to allow unambiguous interpretation of microgravity results.

The key to addressing the dual issues of understanding and controlling the distribution of water and air in the root zone is the ability to measure the water status of the media in microgravity. Sensors must be compatible with the limited mass, volume, and power constraints common to space flight. Use of electromagnetic sensors is restricted in space flight due to possible interference with navigational and communications equipment (22). The objective of this study was to test tensiometers and heat-pulse sensors for measurement of matric potential and water content in porous media during space flight. The tests were conducted during parabolic flight (KC-135), which provides $g$-force ranging from 1.8 to $0 \mathrm{~g}$. Current understanding of how these sensors perform in variable gravity or how water configures and redistributes itself in a microgravity environment is an ongoing area of research.

\section{MATERIALS AND METHODS}

\section{KC-135 Microgravity Flight Profile}

The KC-135 flight was initiated from Ellington Field as part of the Reduced Gravity Program through the National Aeronautics and Space Administration (NASA) at the Lyndon B. Johnson Space Center (JSC) in Houston, TX (12). The flights were conducted daily from September 17 to 20, 2002. The $\mathrm{KC}-135$ is a four-engine turbojet aircraft similar to the commercial Boeing 707. The aircraft flies a profile where it descends at a $45^{\circ}$ angle down to 24,000 $\mathrm{ft}$ (experiencing elevated gravity for 40-60 s), then pulls up at a $45^{\circ}$ angle to $32,000 \mathrm{ft}$. At the top, the aircraft is nosed over and 20-25 s of microgravity are experienced. Typically, 10 microgravity parabolas are completed in succession followed by a break as the plane turns around for another run in the opposite direction. The aircraft can also fly profiles to induce lunar gravity (one sixth $g$ ) and Martian gravity (one third $g$ ) conditions (12).

During flight pressure regulators on the plane maintain cabin pressure at the equivalent of $5000 \mathrm{ft}$ altitude. In reality, cabin pressure is known to vary by about $3 \mathrm{kPa}\left(30 \mathrm{~cm} \mathrm{H}_{2} \mathrm{O}\right)$ during the parabolas. Cabin pressure was not measured during the experiment.

\section{Substrate Compartment}

The basic container was a clear polycarbonate (Lexan) plastic compartment $(25.8 \mathrm{~cm} \mathrm{~L} \times 4.4 \mathrm{~cm}$ $\mathrm{W} \times 7.0 \mathrm{~cm} \mathrm{H} \times 0.5 \mathrm{~cm}$ thick) with a $1.3-\mathrm{cm}$ OD plastic porous tube (20-30 $\mu \mathrm{m}$ pore size; Porex Corp., Fairburn, GA USA) running the length of the compartment. The center of the plastic tube was mounted $2.0 \mathrm{~cm}$ from the exterior bottom of the compartment. The porous tube was equipped with fittings that allowed water to be added to the compartment using a syringe. The configuration was representative of the flight configuration for the WONDER space flight experiment $(5,9,10)$. The cover was also made of clear polycarbonate plastic and had four 9-mm-diameter tapped holes drilled at an on-center spacing of $5 \mathrm{~cm}$. The holes were used to mount the tensiometers.

Before the particulate medium was added, eight heat-pulse water content sensors were mounted at 5.0$\mathrm{cm}$ spacing along each side of the substrate compartment (Fig. 1). Two sensors were placed at depths of $2.0,3.0,4.0$, and $6.0 \mathrm{~cm}$ from the top edge. The compartment was then completely filled with $312.05 \mathrm{~g}$ of oven-dried Turface Pro League ${ }^{\circledR}$ sieved to a particle size of 1-2 mm (Profile Products LLC, Buffalo Grove, IL). Turface was compacted to a bulk density of 0.644 using a narrow blunt object. When Turface was added attention was paid to ensure the sensors were surrounded by the medium and not pressed up against the plastic sides. The medium was naturally saturated (allowing air entrapment) over a period of several hours by injecting $60 \mathrm{ml}$ of water every 30 min until the medium surface was covered with a water film. The saturated volumetric water content (VWC) was 0.67. 


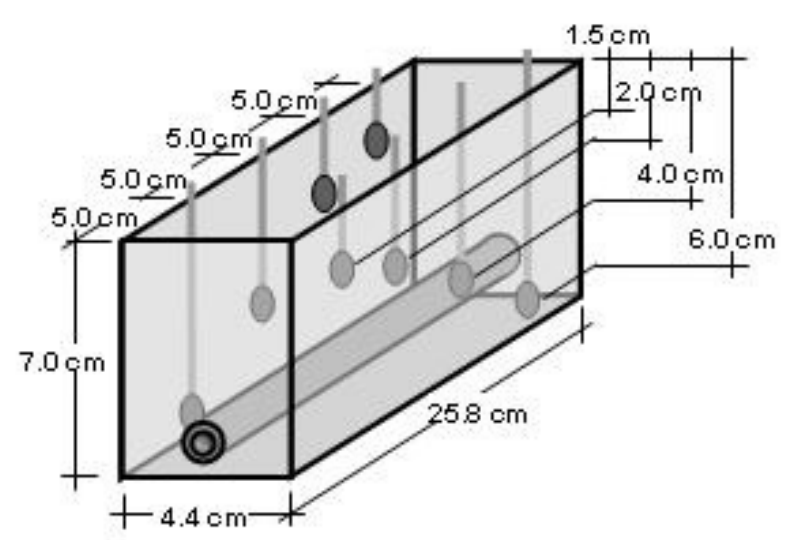

Figure 1. Positioning of the heat-pulse sensors in the substrate compartment prior to the addition of 1-2 mm particle size Turface medium. Water inflow and outflow from the medium was through the microporous plastic tube located at the bottom of the compartment.

A set of four presaturated and water-filled minitensiometers were vertically mounted through the cover of the substrate compartment and slowly positioned into the wetted media. Once the tensiometers were in place, the cover was screwed into the body of the compartment. Tests revealed the cover's seal was not air tight. The wetted substrate compartment was placed in a clear plastic glovebox inside the KC-135 for containment of water and media (Fig. 2).

The medium had a VWC of 0.67 for the first flight. Thereafter water was removed from the medium through the porous tube (Fig. 1) at the end of each flight so that water content equilibration within the medium could occur before the next flight on the following day. During the course of the week the spectrum of water contents from saturated to nearly complete macropore drainage was covered (Table 1). Average volumetric water contents of the bulk medium in the compartment were calculated from daily changes in mass. Also shown in Table 1 are the typical preflight matric potentials measured by the tensiometers.

\section{Substrate-Water Characteristic}

The fundamental physical relationship for porous media describing water content and matric potential

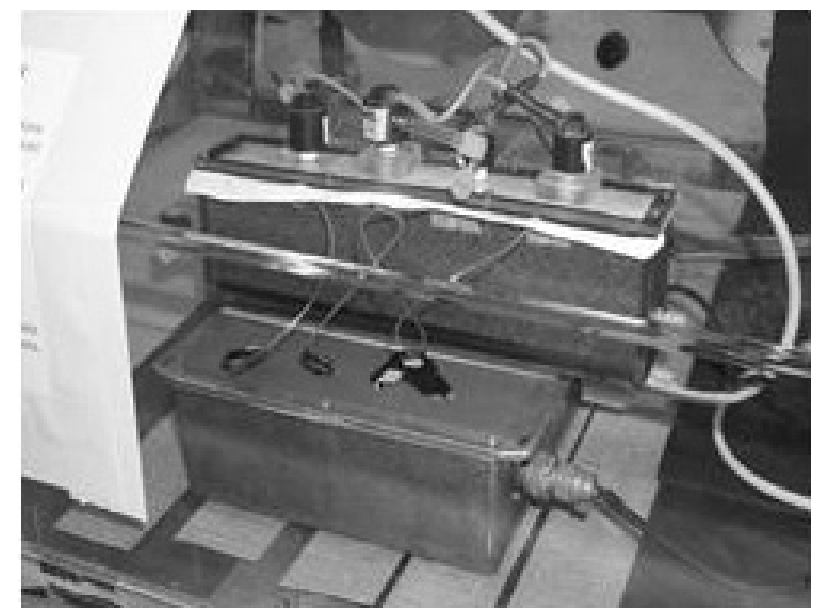

Figure 2. Test set-up during flight. The four tensiometers are mounted on top of the substrate compartment (background). Four of the eight TMAS sensor leads are connected through the top of the sensor control box (foreground). The apparatus was contained in a clear plastic glovebox.

forms the foundation for many other physical phenomena. An effective and commonly used parametric model for relating $\theta$ to the matric suction, $h$, was proposed by van Genuchten (25), given as

$$
\Theta=\frac{\theta-\theta_{r}}{\theta_{s}-\theta_{r}}=\left[\frac{1}{1+(\alpha|h|)^{n}}\right]^{m}
$$

where $\Theta$ is the relative water content or saturation, $\theta_{\mathrm{r}}$ and $\theta_{\mathrm{s}}$ are the residual and saturated water contents,

Table 1. Preflight Volumetric Water Contents and Matric Potentials for $1 \mathrm{~g}$, Ground Conditions

\begin{tabular}{|c|c|c|c|}
\hline $\begin{array}{l}\text { Average Vol. } \\
\text { Water Content }^{\mathrm{a}}\end{array}$ & $\begin{array}{l}\text { Average Matric } \\
\text { Potential }(\mathrm{cm})^{\mathrm{b}}\end{array}$ & $\begin{array}{l}\text { Corrected Matric } \\
\text { Potential }(\mathrm{cm})^{\mathrm{c}}\end{array}$ & $\begin{array}{c}\text { Flight } \\
\text { Day }\end{array}$ \\
\hline 0.67 & -1.3 & 0 & 1 \\
\hline 0.60 & -5.2 & -3.9 & 2 \\
\hline 0.49 & -7.9 & -6.6 & 3 \\
\hline 0.41 & -11.2 & -9.9 & 4 \\
\hline
\end{tabular}

${ }^{a}$ Average volumetric water content of medium in the compartment was calculated from the daily removal of water.

${ }^{\mathrm{b}}$ Average matric potential measured by the four tensiometers using preflight calibration.

${ }^{c}$ Average matric potential of the four tensiometers adjusted to read 0 in saturated medium. 
respectively, and $\alpha, n$, and $m$ are parameters directly dependent on the shape of the $\theta(h)$ curve, and the assumption that $m=1-1 / n$ is often used. Parameters for the van Genuchten (25) retention model are listed in Table 2.

For aggregated porous media, it may be sufficient to characterize water retention only within the macropore domain shown in Figure 3, because little water held within the internal aggregate pores (micropores) is available to plants (e.g., in this case a two order of magnitude decrease in matric potential before release of water from the micropores). Macropore water held between millimeter-sized aggregates may be removed using modest suction (e.g., 5-15 $\mathrm{cm} \mathrm{H}_{2} \mathrm{O}$ ). Steinberg and Henninger (23) documented plant wilting occurred when the macropores of 0.25-1 mm aggregate (Profile Products LLC, Buffalo Grove, IL) were drained (volumetric water content of $\sim 40 \%$; suction $-20 \mathrm{~cm} \mathrm{H}_{2} \mathrm{O}$ ). Plant water use measurements showed that $75 \%$ of plant extractable water had been exhausted at this point. Both the 12-mm and 0.25-1-mm aggregates are made from the same material; thus, internal aggregate pore space (micropore) is the same for both particle size distributions. Figure 3 illustrates measured and modeled wetting and draining water retention curves for the 1-2-mm aggregated calcined clay used in this study, revealing the low range of matric suction at which water is drained. Note the large water content change that occurs over a relatively small matric suction range. Included in the figure is the preflight volumetric water content plotted against the average ten-

Table 2. Substrate Parameters Described by the van Genuchten (25) Water Retention Model and Measured Physical Characteristics

\begin{tabular}{lcc}
\hline Parameter & $\begin{array}{c}\text { Turface 1-2 mm } \\
\text { Drying Curve }\end{array}$ & $\begin{array}{c}\text { Turface 1-2 mm } \\
\text { Wetting Curve }\end{array}$ \\
\hline$\alpha\left(\mathrm{m}^{-1}\right)$ & 40.7 & 20.4 \\
$n$ & 3.98 & 6.39 \\
$m$ & 0.749 & 0.843 \\
$\theta_{\mathrm{r}}$ & 0.35 & 0.35 \\
$\theta_{\mathrm{s}}$ & 0.68 & 0.68 \\
\hline
\end{tabular}

Saturated hydraulic conductivity $\left(\mathrm{cm} \mathrm{s}^{-1}\right): 1.26-2$

Bulk density $\left(\mathrm{g} \mathrm{cm}^{-3}\right): 0.64$

Particle density $\left(\mathrm{g} \mathrm{cm}^{-3}\right): 2.5$ (provided by the manufacturer) Total porosity: 0.74

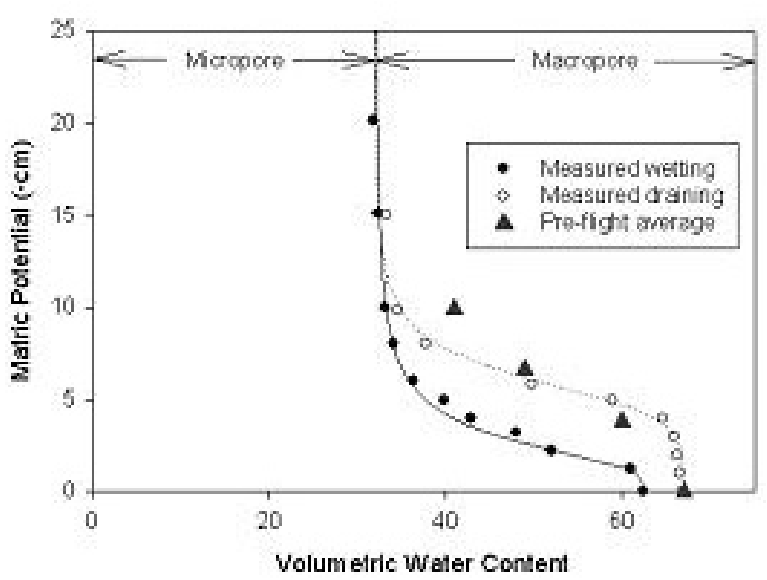

Figure 3. Substrate-water characteristic (SWC) curves fitted to 1-2 mm Turface measurements for both wetting and drying processes. Lines were fitted using Equation (1). Preflight average represents container volumetric water content and the average matric potential measured at all four depths corrected to 0 at saturation.

siometer reading based on the four sensors. The saturated matric potential reading that occurred on flight 1 was used to provide a common offset for each daily matric potential value where each succeeding flight contained less water than the previous day (Table 1). In this "draining mode," the averaged data in Figure 3 correspond most closely with the draining curve model as expected. Differences in the sample height between the flight cell $(\sim 6 \mathrm{~cm})$ and the sample $(\sim 1$ $\mathrm{cm})$ whose measured data were fit using Equation (1) may account partially for differences shown in Figure 3.

\section{Heat Pulse Sensors}

The single-probe sensors contain both heating and temperature-sensing elements in the head. The two components are contained in a resin bead that has the dimensions of $2.5 \times 2.5 \times 7.6 \mathrm{~mm}$ (Fig. 4). The sampling volume of the sensors is $0.5 \mathrm{~cm}^{3}(11)$. The design of the heat-pulse sensors was based on soil moisture sensors that were used in previous space flight experiments (19).

The thermal characteristics of water content in porous media has been used as a means of inferring water content in soils and other porous media. The 


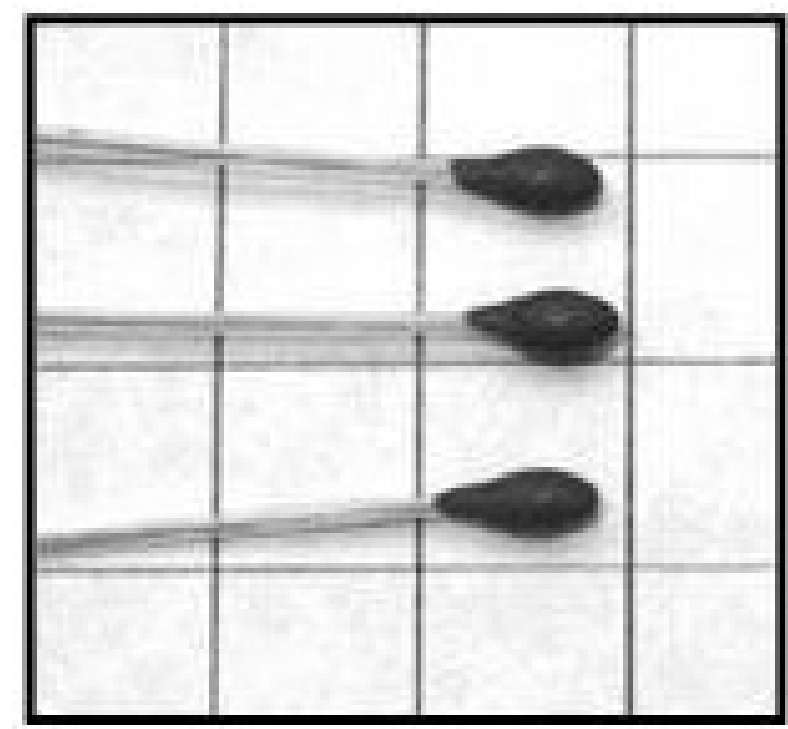

Figure 4. Three heat-pulse sensors (1-cm grids).

theory describing the relationship between soil characteristics and the time-dependent temperature rise due to a heat-pulse from a line source has been well developed $(4,7,20)$. The development of the heatpulse sensors used in this study was based on this theory. Soil moisture measurements are made by first taking a temperature reading, initiating the heat-pulse, then recording the temperature change at the end of the heat-pulse. The temperature change can be correlated to the soil moisture content in the media surrounding the sensors $(4,7,11,14,20)$. The sensors have been modified to give a simplified output, where the temperature increase due to the heat pulse could be correlated to the soil water content (11).

A computer program was developed to allow ondemand heat-pulse measurements. The factory software could only be set to take measurements at regular intervals. This would be inadequate during the KC-135 microgravity flight. Measurements were taken under varying gravity conditions. Data were collected using the custom program that allowed the on-demand activation of the heat-pulse sensors. The program was run on a laptop computer with a hand track mouse (4-D USB; 3 G Green Green Globe Co., Ltd., Taipei, Taiwan) during the flight.

The heat-pulse sensors were calibrated preflight in the laboratory. Two temperature baths were used for temperature calibration: one for temperatures below ambient (Circulating Bath, Forma Scientific) and the other for above ambient temperatures (ISOTEMP 215, Fisher Scientific). The sensors had very linear calibration curves for temperature with $R^{2}$ values from 0.9979 to 0.9982 over temperatures ranging from $10^{\circ} \mathrm{C}$ to $35^{\circ} \mathrm{C}$ (data not shown).

For the soil moisture calibration, $100 \mathrm{ml}$ of packed, oven-dried Turface was placed in a container and $25 \mathrm{ml}$ of water was added to the medium for the $25 \%$ volumetric water content data point. The well-mixed medium was then quickly packed around the sensors in a $7.5 \times 7.5 \times 12.0-\mathrm{cm}$ plastic container. A set of five heat-pulse sensor data points was collected at each water content level. The protocol was repeated adding 50 and $75 \mathrm{ml}$ of water for the 0.50 and 0.75 volumetric water content data points. Data for dry media were also recorded. Four typical heat-pulse soil moisture sensor calibration curves are shown in Figure 5. The soil moisture calibration equations for the set of eight heat-pulse sensors used in the experiment had $R^{2}$ values ranging from 0.9356 to 0.9964 .

\section{Tensiometers}

Operation of the tensiometer was as per the ASTM standard for tensiometers (1). The energy components in centimeter of water head of a tensiometer measurement include the pressure transducer (gage type referencing the cabin atmosphere), $h_{p}$, and the elevation head of the water-filled tube, $h_{z}$, giving the sub-

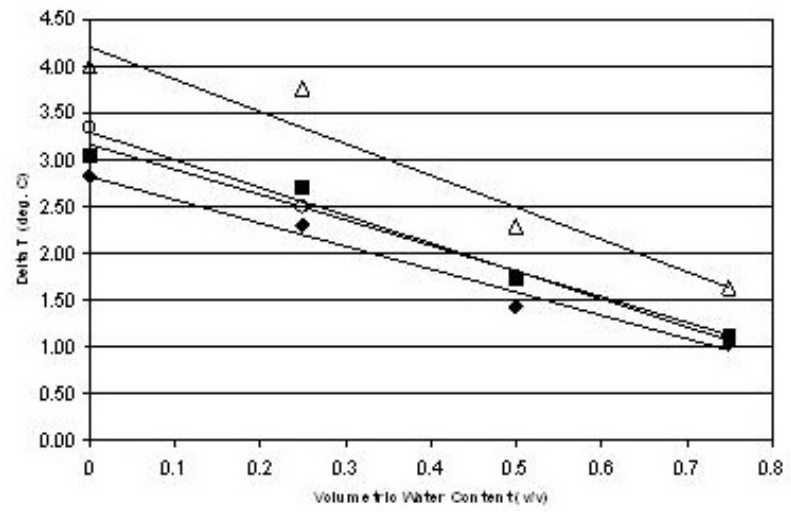

Figure 5. Typical calibration curves for four TMAS sensors. $\diamond$ : sensor $0, \mathbf{\square}$ : sensor $1, \triangle$ : sensor 2 , and $\bigcirc$ : sensor 3. Average values $\pm \operatorname{SDs}(N=5)$. 
strate matric potential relative to atmospheric pressure as measured by the tensiometer, $h_{t}$, as

$$
h_{t}=h_{p}+h_{z}
$$

The conversion between pressure, $P$, in units of $\mathrm{kPa}$ and pressure head, $h$, in units of $\mathrm{cm} \mathrm{H}_{2} \mathrm{O}$ is made using the density of water $\rho_{\mathrm{w}}\left(\mathrm{g} \mathrm{cm}^{-3}\right)$ and the acceleration of gravity on Earth, $g(1)\left(\mathrm{m} \mathrm{s}^{-2}\right)$, where $P=\rho_{\mathrm{w}} \cdot g(1) \mathrm{h}$. In the varying gravity environment produced in the $\mathrm{KC}-135$ flight, the gravitational component, $h_{z}$, is multiplied by the ratio of gravitational forces, $g(t) / g(1)$, giving

$$
h_{t}=h_{p}-h_{z} \cdot \frac{g(t)}{g(1)}
$$

where $g(t)$ is the instantaneous $g$ force at time $(t)$ as measured by accelerometers in flight.

The tensiometers were constructed of a $4.8-\mathrm{mm}$ diameter stainless steel cup (pore size 5 or $10 \mu \mathrm{m}$ ) epoxied to a stainless steel tube (3.2 $\mathrm{mm}$ ID). The pore sizes were chosen to obtain equilibrium quickly during the microgravity portion of the flight. A pressure transducer (Fig. 6) was attached to the tube via a machined plastic fixture (Delran body). A bidirectional gauge pressure transducer with a range of \pm 70 $\mathrm{cm}_{2} \mathrm{O}$, a response time of $1 \mathrm{~ms}$, and an accuracy of $0.4 \%$ full span was used to sense vacuum within the

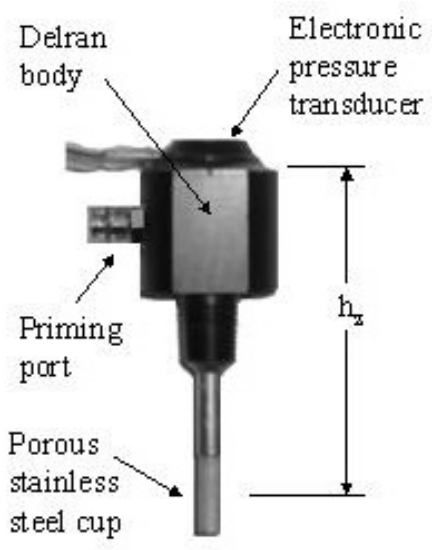

Figure 6. Tensiometer comprised of a pressure transducer measuring the pressure head, $h_{p}$, and porous membrane where the tensiometer measured matric head, $h_{t}$, is determined from the elevation difference, $h_{z}$. tensiometer (PX40, Omega Engineering, Stamford, $\mathrm{CN})$. The pressure sensors were connected to a datalogger (23X; Campbell Scientific, Logan, UT) and the tensiometer pressure at the transducer and aircraft accelerometer data were recorded at 1-s intervals. Both the tensiometers and medium were referenced to ambient cabin pressure.

\section{RESULTS AND DISCUSSION}

\section{Heat-Pulse Sensors}

The heat-pulse sensors performed for each flight. High- $g$ measurements were not made during the first flight due to a hardware problem with the laptop computer. No further problems with laptop operations were experience for the remaining flights. The datalogger used with the tensiometers did not experience any problems during the testing period.

Figures 7 and 8 show that variable gravity had no significant effects on the soil moisture measurements. Figure 7 also shows that the heat-pulse sensor averages overestimated the VWC of the substrate compartment, especially as the substrate became drier. For example, on day 4 the bulk volumetric water content was 0.41 , whereas the heat-pulse sensors recorded 0.60 .

There are several reasons for the poor performance of the heat-pulse sensors in drying medium. Firstly, overestimation of soil moisture has been previously attributed to the small sampling volume

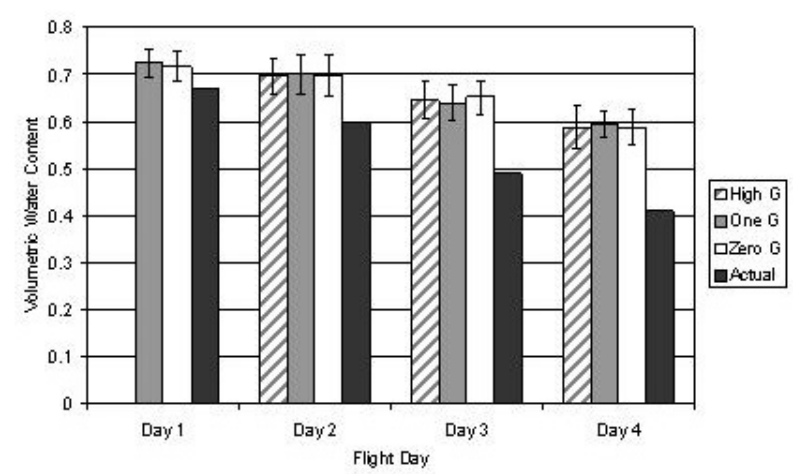

Figure 7. Effects of variable gravity on the volumetric water content levels measure by heat-pulse. High- $g>1.1 \mathrm{~g}, 1.1$ $g>$ One-G $>0.1 \mathrm{~g}$, zero $\mathrm{g}<0.1 \mathrm{~g}$. The values plotted are the average of all eight sensors $\pm \mathrm{SD}$. 
and positioning of the sensors (13). Secondly, sensors were calibrated in the laboratory, not in situ. Output of the heat-pulse sensor is determined primarily by the thermal conductivity of the medium, and thermal conductivity is known to be strongly influenced by particle arrangement (geometry of particle to particle contact). Rearrangement of particles due to repacking of sensors or plane vibration and changing $g$-forces during KC-135 flight could alter the conductivity and thus change sensor calibration (Kluitenberg, personal communication, 2003). A comparison of known preflight data points using previously derived calibration curves showed deviations of $10 \%$ or more between the known values and the calibration curve outputs (data not shown). The discrepancy was presumably due to the repacking of the medium around the sensors. Ground versus flight calibration of thermal conductivity sensors for media water content measurement is an area of future study.

Figure 8 shows that at the different depths in the soil profile the effects of variable gravity were not significant. There was no consistent trend in the heatpulse data to suggest zero- or high- $g$ influenced the measurements.

\section{Tensiometers}

Figure 9 shows the effect of rapidly changing gravity on the tensiometer operation and the matric po-

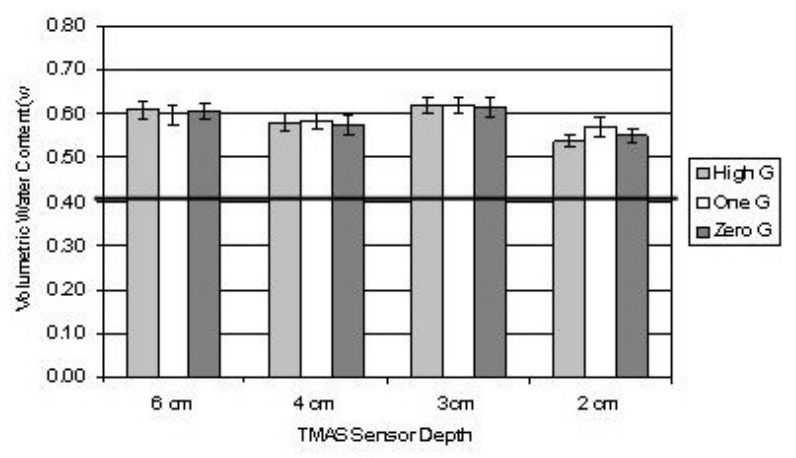

Figure 8. Effects of variable gravity on the volumetric water content levels at different depths measured by heat-pulse. High$g>1.1 \mathrm{~g}, 1.1 \mathrm{~g}>$ One-G $>0.1 \mathrm{~g}$, zero $\mathrm{g}<0.1 \mathrm{~g}$. The values plotted are the averages of two sensors at the same depth. The heavy line represents the actual volumetric water content $(0.41)$ on the final day. tential of the medium. The tension in the pressure transducer port (Tp) decreases during 1.8- $g$ period and gradually increased during $0 \mathrm{~g}$. A correction for the gravitational pressure head induced by the water column within the vertically oriented tensiometer was calculated from Equation (3) and is simply a scaled reflection of the gravity force. The correction was added to the measured tension, yielding the corrected matric potential as seen by the porous cup (see Fig. 9.). The potential of the water column increases during the 1.8- $\mathrm{g}$ period and decreases to 0 during the 0 $g$ period in direct relation to the measured $g$ force $[g(t) / g(1)]$. The water tension at the porous cup, assumed to be in equilibrium with the porous medium water, showed several interesting phenomenon. Firstly, in the saturated medium (Fig. 9A) the matric potential showed an increase of about $4 \mathrm{~cm}$ during
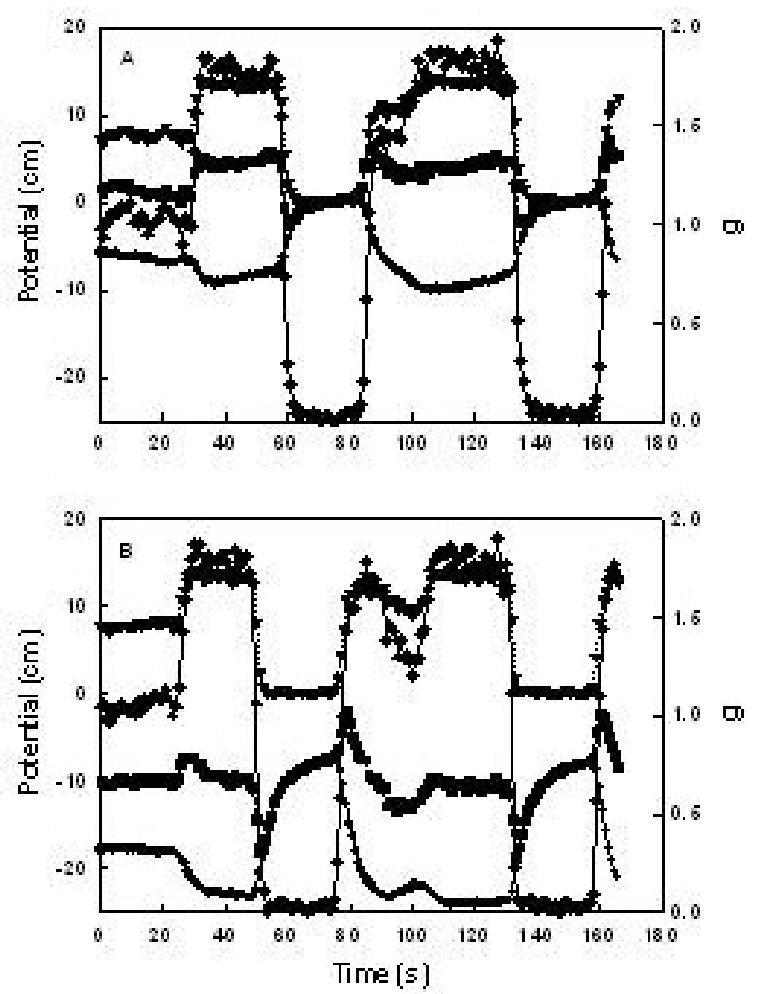

Figure 9. Effect of variable $g(\bullet)$ on measured tension in the pressure transducer port $(\bullet)$, calculated internal water column potential $(7.5 \mathrm{~cm})(\boldsymbol{\nabla})$, and corrected tension in the porous cup (matric potential) $(\boldsymbol{\square})$ for saturated (volumetric water content $=0.68)(\mathrm{A})$ and dry (volumetric water content $=0.41)(\mathrm{B})$ 1-2 mm Turface. Tensiometer cup was at a depth of $4 \mathrm{~cm}$. Data show first two parabolas out of the set of 10 . 
the $0-g$ to $1.8-g$ transition. This increase was due to the water pressure head within the porous medium arising from a 4-cm depth of satiated porous medium. In addition, during the transition from $1.8 \mathrm{~g}$ to $0 \mathrm{~g}$ and visa versa a transient spike appears in the matric potential data. This was due to the lag between the rate of water movement within the porous medium (and possibly through the cup), which decreases with decreasing water content, the instantaneous effect of $g$ on the pressure head of the water column within the tensiometer, and the tensiometer response measured by the pressure transducer. The magnitude of the transient spikes is greater in drier medium than saturated medium, supporting the rate of change lag between the calculated internal water column potential and measured tension at the pressure transducer (Fig. 9B). On the fourth flight, in the driest medium tested, the change in matric potential from $0 \mathrm{~g}$ to 1.8 $g$ is a 0 to $-1 \mathrm{~cm}$ decrease, indicating little or no water movement. Smaller changes in $g$ force also affect matric potential. The quality of $g$ force (noise) during the parabola has a nearly instantaneous effect on matric potential within the medium as can be seen during a momentary deviation from $1.8 \mathrm{~g}$ during the second parabola of Figure 9B.

The effect of the porous medium unsaturated hydraulic conductivity can be seen in Figure 10,

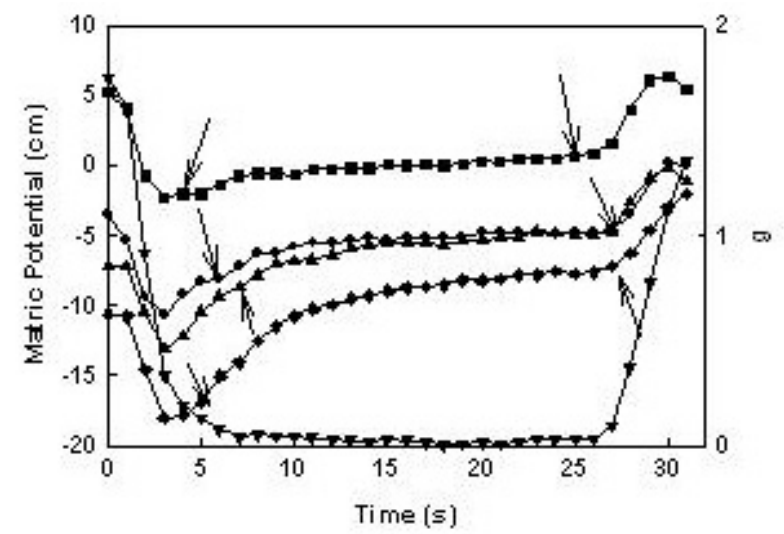

Figure 10. Equilibration of matric potential during $0 \mathrm{~g}$ for $1-2$ mm Turface of different water contents. Measurements were made at a depth of $4 \mathrm{~cm}$; the total depth of Turface in the root module was $6 \mathrm{~cm}$. Volumetric water contents: $\mathbf{\square}=0.68, \boldsymbol{Q}=0.61$, $\boldsymbol{\Delta}=0.49$, and $\boldsymbol{\nabla}=0.41$. Acceleration of gravity $[g(t) / g(1)]=\boldsymbol{\nabla}$. Arrows represent the beginning and ending of $0 \mathrm{~g}$ for each parabola. which illustrates the transition toward an equilibration matric potential during $0 \mathrm{~g}$ for four different water contents. As volumtetric water content was reduced from 0.67 to 0.41 , the commensurate reduction in unsaturated hydraulic conductivity was nearly four orders of magnitude, which causes a slower transition toward equilibration during $0 \mathrm{~g}$ (24). For saturated media the total matric potential change is about $0.5-1 \mathrm{~cm}$, indicating that there is little air space to be displaced by water movement in response to the changing gravity force. For the driest media the change during $0 \mathrm{~g}$ is about 10 $\mathrm{cm}$.

\section{CONCLUSION}

Microgravity testing of soil moisture sensors and tensiometers was completed on a KC-135 aircraft flying a parabolic profile. The test conditions were vigorous due to varying gravity levels that cycled (or alternated) from 1.8 to $0 \mathrm{~g}$ over 40 parabolas per flight. The microgravity environment occurring at the top of the parabola lasted for 20-25 s. The heat-pulse sensor measurements consistently overestimated water content of Turface under all gravity conditions. The heat-pulse sensors have a small sampling volume $\left(0.5 \mathrm{~cm}^{3}\right)$, which makes moisture changes throughout the entire substrate compartment difficult to determine. The tensiometers were able to track apparent changes in matric potential, but these measurements may have been influenced by the vertical orientation and ambient cabin air pressure changes, which may not have been readily translated into the partially sealed porous medium container. Future improvements in matric potential measurement during variable $g$ should address minimization of internal water volume to improve response time, horizontal orientation to minimize the effect of $g$ on gravitational water head within the tensiometer, and either independent cabin pressure measurements and a well-sealed medium container or both pressure transducer and medium adequately referenced to cabin air pressure.

Acknowledgments - This research was supported by NASA's Advanced Life Support Flight Program, NASA grants NAG10291, NCC10-52, and NAG9-1399. 


\section{BIOGRAPHICAL NOTES}

Joey H. Norikane (B.S. Mechanical Engineering, M.S. Agricultural and Biosystems Engineering, Ph.D. Bio-Environmental Engineering) is currently an assistant professor in the Biosystems and Agricultural Engineering Department at the University of Kentucky. His field of research is controlled environment agriculture production. Prior to becoming a faculty member, he completed a post-doc at the NASA Kennedy Space Center.

Scott B. Jones is currently an assistant professor in the department of Plants, Soils and Biometeorology at Utah State University. His interests are in porous media characterization and instrumentation including electromagnetic measurement techniques. His Ph.D. research presented a framework for optimizing liquid and gas fluxes to plant roots in a microgravity environment in porous media. He is currently a co-investigator on two NASA-funded projects: ORZS, and a study of soil physics in microgravity.

Susan L. Steinberg (B.S. General Agriculture, M.S. Horticulture, Ph.D. Horticulture) is a Senior Research Scientist with Universities Space Research Association and works in the Advanced Life Support Program at Johnson Space Center. She has been involved with NASA-related work since 1995 during which time she has focused on plant water relations, and solid substrate growth medium and water delivery systems. Currently she is Principal Investigator for Flow and Distribution of Fluid Phases Through Porous Plant Growth Media in Microgravity, a NASAfunded research project aimed at understanding control of water and air in the root zone of plants in microgravity.

Howard G. Levine (B.S. Zoology, M.S. Marine Science, Ph.D. Botany) is a Project Scientist for NASA's Biological Science Office at Kennedy Space Center (KSC). His involvement in space biology began in 1988 with the CHROMEX-1 experiment. Since then he has participated in 24 spaceflight experiments either as a science team member or in a project management capacity. He has 53 space-related publications that include results from plant and aquatic organism research plus hardware and protocol development efforts. Currently, Dr. Levine is Principal Investigator for the WONDER spaceflight payload that is in development for launch no earlier than 2006.

Dani Or is currently the Northeast Utilities Foundation Chair Professor of Environmental Engineering at the University of Connecticut. Professor Or specializes in modeling and measurement of mass and energy flow and transformation in porous media; use of electromagnetic methods to characterize soil constituents and geometrical factors; modeling and measurement of soil structural dynamics affecting hydraulic properties; modeling pore scale liquid retention, film and corner flow, and interfacial processes; modeling intermittent and unstable flows in fractured rock; and study of pore scale physical constraints on biological activity in unsaturated porous media. He is currently a co-investigator on two NASA-funded projects: ORZS, and a study of soil physics in microgravity.

\section{REFERENCES}

1. ASTM. Standard guide for measuring matric potential in the vadose zone using tensiometers. D 3404-91; 1998.

2. Bingham, G. E.; Levinskikh, M. A.; Sytchev, V. N.; Podolsky, I. G. Effects of gravity on plant growth. J. Gravitat. Phys. 7:5-8; 2000.

3. Bingham, G.; Jones, S. B.; Podolsky, I.; Yendler, B. S. Porous substrate water relations observed during the greenhouse-2 flight experiment. Society of Automotive Engineers (Techn. Paper 961547). Warrendale, PA: SAE; 1996.

4. Bristow, K. L.; White, R. D.; Kluitenberg, G. J. Comparison of single and dual probes for measuring soil thermal properties with transient heating. Aust. J. Soil Res. 32:447464; 1994.

5. Burtness, K. A.; Norwood, K. L. L.; Levine, H. G. Development of a porous tube based plant growth apparatus. Society of Automotive Engineers/International Conference on Environmental Systems (SAE/ICES) (Paper No. 2002-012389), San Antonio, TX, July 15-18, 2002.

6. Dutcher, F. D.; Hess, E. L.; Halstead, T. W. Progress in plant research in space. Adv. Space Res. 14:159-171; 1994.

7. Jackson, R. D.; Taylor, S. A. Thermal conductivity and diffusivity. In: Klute, A., ed. Methods of soil analysis part 1-physical and mineralogical methods. Madison, WI: American Society of Agronomy, Inc.; 1986.

8. Jones, S. B.; Or, D. Microgravity effects on water flow and distribution in unsaturated porous media: Analysis of flight experiments. Water Resour. Res. 35:929-942; 1999.

9. Levine, H. G., Tynes, G. K.; Norikane, J. H.; Burtness, K. A. Evaluation of alternative water input modes for spacebased plant culture applications. Society of Automotive Engineers/International Conference on Environmental Systems (SAE/ICES) (Paper No. 2002-01-2381), San Antonio, TX, July 15-18, 2002.

10. Levine, H. G.; Norikane, J. H.; Rouzan, D. T.; Best, M. D.; Murdoch, T.; Burtness, K. Development of technology and experimental designs for plant growth studies in space. Proceedings of the 40th Space Congress, Cape Canaveral, FL, April 29-May 1, 2003.

11. Morrow, R. C.; Crabb, T. M.; Anderson, R. J.; Smith, D. J. A microprocessor based soil moisture sensor system for space based plant growth units. Society of Automotive Engineers/International Conference on Environmental Systems (SAE/ICES) (Paper No. 01ICES-301), Orlando, FL, July 9-12, 2001.

12. NASA. KC-135 reduced gravity research. National Aeronautics and Space Administration, Johnson Space Center. Available at: http://jsc-aircraft-ops.jsc.nasa.gov/kc135/ index.html (accessed April 22, 2003)

13. Norikane, J. H.; Tynes, G. K.; Frazier, M. C.; Levine, H. G. Evaluation of two soil moisture sensor designs for space- 
flight applications. Society of Automotive Engineers/International Conference on Environmental Systems (SAE/ ICES) (Paper No. 2002-01-2385), San Antonio, TX, July 15-18, 2002.

14. Orbital Technologies. Temperature \& moisture acquisition system user manual (beta version). Orbital Technologies Corp.; 2001.

15. Podolsky, I.; Mashinsky, A. Peculiarities of moisture transfer in capillary-porous soil substitutes during space flight. Adv. Space Res. 14:39-46; 1994.

16. Porterfield, D. M.; Barta, D. J.; Ming, D. W.; Morrow, R. C.; Musgrave, M. E. Astroculture root metabolism and cytochemical analysis. Adv. Space Res. 26:315-318; 2000.

17. Porterfield, D. M.; Dreschel, T. W.; Musgrave, M. E. A ground-based comparison of nutrient delivery technologies originally developed for growing plants in the spaceflight environment. HortTechnology 10:179-185; 2000.

18. Richards, L. A. Capillary conduction of liquids in porous mediums. Physics 1:318-333; 1931.

19. Salisbury, F. B. Growing super-dwarf wheat in Space Station Mir. Life Support Biosphere Sci. 4:155-166; 1997.
20. Shiozawa, S.; Campbell, G. S. Soil thermal conductivity. Remote Sensing Rev. 5(1):301-310; 1990.

21. Simunek, J.; Sejna, M.; van Genuchten, M. T. The HYDRUS-2D software package for simulating water flow and solute transport in two-dimensional variably saturated media. Golden, CO: International Ground Water Modeling Center, Colorado School of Mines; 1996.

22. Steinberg, S. L.; Ming, D. W.; Henninger, D. Plant production systems for microgravity: Critical issues in water, air and solute transport through unsaturated porous media. NASA/TM-2002-210774. NASA/JSC; 2002.

23. Steinberg, S. L.; Henninger, D. L. Response of the water status of soybean to changes in soil water potentials controlled by the water pressure in microporous tubes. Plant Cell Env. 20:1506-1516; 1997.

24. Steinberg, S. L.; Poritz, D. Measurement of hydraulic characteristics of porous media used to grow plants in microgravity. Soil Sci. Soc. Am. J. 69: in press.

25. van Genuchten, M. T. A closed-form equation for predicting the hydraulic conductivity of unsaturated soils. Soil Sci. Soc. Am. J. 44:892-898; 1980. 